\title{
Suboptimal Choices and the Need for Experienced INDIVIDUAL WeLL-BeING in ECONOMIC ANALYSIS
}

\author{
Christopher K. Hsee \\ Yuval Rottenstreich \\ Alois Stutzer \\ (University of Chicago GSB) \\ (New York University) \\ (University of Basel)
}

\begin{abstract}
Standard economic analysis assumes that people make choices that maximize their utility. Yet both popular discourse and other fields assume that people sometimes fail to make optimal choices and thus adversely affect their own happiness. Most social sciences thus frequently describe some patterns of decision as suboptimal. We review evidence of suboptimal choices that arise for two reasons. First, people err in predicting the utility they may accrue from available choice options due to the evaluation mode. Second, people choose on the basis of salient rules that are unlikely to maximize utility. Our review is meant to highlight the possibility of a research program that combines economic analysis with measures of individuals' experienced well-being to improve people's happiness.

Keywords: suboptimal choice, individual well-being, experienced utility, evaluation mode, salient rule, utility misprediction

JEL classifications: D01, D11, D60, D91
\end{abstract}

\section{Addresses:}

Hsee: University of Chicago, Booth School of Business, 5807 South Woodlawn Avenue, Chicago, IL 60637, email: chris.hsee@chicagogsb.edu.

Rottenstreich: New York University, Leonard N. Stern School of Business, Tisch Hall, 40 West 4th Street, New York, NY 10012, email: yuval@stern.nyu.edu.

Stutzer: University of Basel, Faculty of Business and Economics, Peter Merian-Weg 6, 4002 Basel, Switzerland, email: alois.stutzer@unibas.ch.

\footnotetext{
* Revised version for the International Journal of Happiness and Development, May 2012.
} 
In this article we advocate using economics in combination with measures of experienced well-being to analyze how people can improve their choices. To introduce the issue, consider, for example, a fundamental result in consumer choice: that within each period the ratio of marginal utility to price should be equal across all goods. In principle, this result can help diagnose suboptimal choices and indicate appropriate prescriptions. For instance, an individual might ponder the aforementioned ratios, conclude that they are not equal for him or her, implying that he or she is choosing too much of some goods and too little of others, and adjust accordingly.

In practice, the possibility of such diagnoses and prescriptions is almost never pursued. Instead, in traditional economics, it is common to presume that people are making choices in an optimal manner. That is, it is common to presume that people are making choices that maximize their happiness and cannot be improved upon (given extant budget and other constraints).

An entirely different perspective prevails in popular discourse and most other disciplines. There, it is common to presume that people attempt to maximize their happiness but may not always be effective at doing so. The notion of (non random) mistaken choices, alien to standard economics, is part and parcel of both daily life and most social sciences. ${ }^{1}$ If people pursue happiness, but are not always good at achieving it, then one reason might be that people sometimes choose options that are suboptimal for them. Accordingly, outside of standard economics, it is common to encounter prescriptions suggesting that certain consumption profiles yield greater satisfaction than others, and that people would be better off if they switched their default choices towards these alternative profiles.

Our aim here is to lay out - what we find to be - intriguing findings from empirical studies where choices are observed and experiences are rated. Our review contributes to the cross-disciplinary field of economics and psychology (see, e.g., Akerlof and Shiller, 2009; Camerer, Loewenstein \& Rabin, 2004; De Cremer, Zeelenberg \& Murnighan, 2006; Frey \& Stutzer, 2007; Rabin, 1998) and establishes a closer link between the study of suboptimal choices and the research on

${ }^{1}$ Influential books applying this perspective include those by Gilbert (2006), by Kahneman (2011) and by Thaler and Sunstein (2008). 
experienced well-being. In the last few decades, psychologists, sociologists, anthropologists, as well as a growing number of economists have accumulated a large volume of field data and experimental results on the pursuit of happiness and have formulated intriguing, testable theories of happiness (e.g., Diener, Kahneman \& Helliwell, 2010; Di Tella \& MacCulloch, 2006; Easterlin, 2010; Frey \& Stutzer, 2002; Kahneman, Diener \& Schwarz, 1999; Layard, 2005; Stutzer \& Frey, 2010; van Praag \& Ferrer-i-Carbonell, 2004; Veenhoven, 1993).

Our review is meant to be illustrative rather than exhaustive; it focuses on two types of suboptimal choices, which are best introduced using a framework put forth by Kahneman and Snell (1992). Let $C(X)$ be an individual's chosen consumption profile given the possibility set $X$. Let $U(x, X)$ be the experienced utility (or happiness) the individual accrues from the consumption of $x$ given the possibility set $X$. Finally, let $P(x, X)$ be the individual's decision-time prediction of $U(x, X)$. Ideally, within this framework, people would accurately predict the utility they will accrue from each option; that is, $P$ would be consistent with $U$, at least in expectation. Moreover, people should choose the option with the greatest predicted utility; that is, $C$ should maximize $U$ (and $P$ ), again at least in expectation. It could be said, then, that optimal choice requires consistency of $C, P$, and $U$. In traditional economics, this consistency is reached by assumption. However, a great deal of data indicates that these variables are often inconsistent, yielding suboptimal choices. The two types of suboptimal choices we review either implicate a particular way in which $C, P$, and $U$ can become inconsistent or suggest a discrepancy from the framework altogether (for related analyses see Benjamin et al., 2012; Gilbert \& Wilson, 2009; Loeweinstein \& Schkade, 1999; Mellers, 2000; Mellers \& McGraw, 2004; Schkade \& Kahneman, 1998; Wilson \& Gilbert, 2003)

We begin by examining CPU inconsistencies that occur due to differences in "evaluation modes." All evaluations are made in one or some combination of two basic modes: joint and separate. In joint evaluation (JE) mode, people confront multiple options simultaneously. In single evaluation (SE) mode, people are exposed to only one item and evaluate it in isolation. Much experimental work shows that because JE facilitates cross-item comparisons and SE does not, the two modes often yield systematically different revealed preferences. 
We argue that choices usually arise in JE (which of these televisions should I buy?) whereas the consumption that follows from a choice occurs in SE (do I like the television I bought?). In addition, we argue that there is a fundamental bias to predicted utility: people choosing under JE appear to forecast their subsequent accrual of utility as if it too will occur under JE rather than SE. Consequently, systematic suboptimal choices may frequently arise.

We next examine situations in which choice does not follow predicted utility and does not maximize it. These situations highlight a departure from the CPU framework itself. In particular, it appears that people often choose by invoking salient decision rules rather than forming a prediction of utility. To the extent that these decision rules fit the situation in which they are invoked, good choices may ensue. However, we suggest that decision rules are often too broadly applied; that is, they are frequently invoked in situations where they do not fit. Suboptimal choices then ensue. Returning to the language of our CPU framework, whenever decision rules are invoked, suboptimal choice may arise not because predicted utility yields a biased forecast of experience, but because choice does not depend on predicted utility. Indeed, we review experimental demonstrations in which predictions provide highly accurate forecasts of experienced utility, but choice simply does not follow predicted utility and instead depends on some salient rule.

The CPU framework highlights issues that were perhaps first broached by Scitovsky (1976), who some time ago critiqued the standard economic assumption that people necessarily predict utility without bias and choose accordingly as "unscientific," because "it seemed to rule out - as a logical impossibility - any conflict between what man chooses to get and what will best satisfy him (p. 4)." Similar arguments and frameworks have also been elaborated by March (1978), Schelling (1984) and Sen (1982), and most recently by Kahneman and Thaler (2006). The methods for improving happiness that research may eventually suggest will largely come down to aligning $C, P$, and $U$, so that choices indeed depend on predicted utility and that these predictions are unbiased forecasts of accrued utility. We address some normative issues concerning this stance in our concluding remarks. 
We should also note that our focus is primarily on findings identified with behavioral decision research and on studies that consider happiness in terms of moment-by-moment, experienced utility with a specific outcome (cf., Frederickson \& Kahneman, 1993; Kahneman, 2000; Kahneman, Wakker \& Sarin, 1997). Research that examines happiness research in terms of global evaluations of satisfaction with life has recently been reviewed by Stutzer \& Frey (2010). A discussion of the difference between the two approaches is provided by Helliwell (2006), Kahneman and Riis (2005) and Kahneman et al. (2004). Finally we do not address issues examined by the field of positive psychology (e.g., Seligman \& Csikszentmihalyi, 2000; Sheldon, Kashdan \& Steger, 2011) which investigates the impact of internal characteristics such as courage, wisdom, temperance, and humanity on happiness. We are concerned primarily with the effects of consumption on happiness.

\section{A. Evaluation Modes}

As we have mentioned, judgments and choices are made in one or some combination of two basic modes: joint and single. In joint evaluation (JE) mode, people confront multiple options simultaneously. In single evaluation (SE) mode, people are exposed to only one item and evaluate it in isolation. Critically, because JE facilitates cross-item comparisons and SE does not, the two modes may yield systematically different preferences or choices.

\section{A1. Different Preferences in Different Modes}

To illustrate SE and JE preference reversals, consider a study by Hsee (1998) involving two servings of Haagan Dazs ice cream, one involving 7 oz of ice cream contained in a $5 \mathrm{oz}$ cup so it looked over-filled, and the other involving $8 \mathrm{oz}$ of ice cream contained in a 10 oz cup so it looked under-filled. Participants were presented either with both servings side by side, including the ounce information (JE) or with just one of them, also with the ounce information (SE), and indicated their willingness to pay for the item or items. The results revealed a marked preference reversal. In $\mathrm{JE}$, participants were willing to pay more for the $8-0 z$, under-filled serving, but in SE they were willing to pay more for the 7-oz, over-filled serving (even though, objectively, it was worse). 
The preferences are inconsistent in JE and $\mathrm{SE}$, because the attributes that distinguish the two options- amount of ice cream and filling - vary in evaluability. The notion of evaluability refers to how easy or difficult it is to evaluate the desirability of different levels of an attribute when that particular level of the attribute is encountered alone, without other levels as a basis of comparison (Hsee, 1996; Hsee et al., 1999; Hsee \& Hastie, 2006; Hsee, Rottenstreich \& Xiao, 2005; Hsee \& Zhang, 2010).

The amount of ice cream is hard to evaluate in SE. Even if the ounce information is precisely specified; people in SE could not evaluate it with respect to its utility consequences. In contrast, whether a serving is underfilled or overfilled is easy to evaluate. Even without a side-by-side comparison across the two, an overfilled serving seems desirable and an underfilled serving seems undesirable. As a result, when the two servings are encountered in SE, the primary determinant of willingness-to-pay is the easy-to-evaluate filling attribute. However, things change in $\mathrm{JE}$, when people are exposed to the two servings in juxtaposition. In this circumstance, people readily note that one serving contains more ice cream (and also features a bigger cup!). Thus, in JE people are willing to pay more for that serving. Similar evaluability-derived JE-SE preference reversals have been reported in many other contexts (e.g., Bazerman, Loewenstein \& White, 1992; Kahneman, Ritov \& Schkade, 1999; List, 2002). For a more detailed analysis and review on this topic, see Hsee and Zhang (2010).

The crux of our analysis is that in JE people will be sensitive to variation on both easy-to-evaluate and difficult-to-evaluate attributes, whereas in SE people will be sensitive only to variation on easy-to-evaluate attributes and not to variation on difficult-to-evaluate attributes. That is, preferences in the two modes will show systematically distinct weightings of the relevant attributes.

Our JE/SE analysis is also consistent with findings by Ariely, Loewenstein \& Prelec (2003) concerning what these authors term "coherent arbitrariness." For instance, in one of their studies, they observe that the amount of money people demand for exposure to a noise of a given duration can be easily influenced by a random anchor (suggesting arbitrariness) but their subsequent demands for compensation for exposure to noises is highly correlated with duration (suggesting 
coherence). In our terms, the reason that the initial reaction is arbitrary is that it is elicited in SE and it is difficult to evaluate a noise of a particular duration in monetary terms. The reason that subsequent responses are coherent is that they are elicited in JE.

In sum, people in SE are relatively insensitive to variations on difficult-toevaluate attributes (except for variations in sign; sign, after all, is a dichotomous variable $)^{2}$ and sensitive to variations on easy-to-evaluate attributes, and people in JE are sensitive to variations on both types of attributes. Preferences among options will diverge in JE and SE if these options involve a tradeoff between an easy-to-evaluate attribute and a difficult-to-evaluate attribute. Moreover, evaluations under either of the two modes will be more or less accurate with regard to experienced utility.

\section{A2. Predicted Utility versus Experienced Utility: Suboptimal Choices Due to Changing Evaluation Mode}

Consider a hypothetical consumer who is interested in purchasing an apartment and who has narrowed her choices down to two equally expensive options. To simplify matters, assume that the two apartments are essentially identical, except that one is 2000 square feet in size and is in a location where the owner will experience a long commute, and the other is only 1500 square feet in size but is in a location where the owner will experience only a short commute. Now suppose that the consumer chooses to purchase the larger apartment. Here is a critical question: is the consumer's choice likely to maximize her happiness? Or is it a suboptimal choice?

In the context of our example, differences in apartment size are highly evaluable and highly influential under JE at the time of choice, but matter less under SE at the time of the actual home consumption experience. Whether an apartment is 2000 square feet or 1500 square feet is qualitatively similar. In contrast, whether the owner will experience a short or a long commute is an attribute that is likely to make a difference in both choice in JE and subsequent

\footnotetext{
${ }^{2}$ Sometimes even sign is difficult to evaluate, see Ariely, Loewenstein \& Prelec (2003).
} 
experience in SE. Putting these observations together, we suggest that during JE comparison at decision time, the home buyer may believe that living in the larger apartment will make her happier. In subsequent SE consumption, however, having to commute less may lead to a happier life. It is in this way that a suboptimal choice may arise.

Generally speaking, choices are formed comparatively more under JE, whereas consumption unfolds more under SE. Moreover, choosers in JE often fail to recognize or account for the fact that consumption will occur under SE (i.e., alternatives will be less salient) (cf., Gilbert, Driver-Linn \& Wilson, 2002; Van Boven, Dunning \& Loewenstein, 2000; Van Boven \& Loewenstein, 2003; Hsee \& Zhang, 2004).

The analysis above suggests a counterintuitive prescription: encouraging decision-makers to evaluate the choice option separately rather than simultaneously can improve their chances to choose the option that maximizes their consumption experience. The reason is that this strategy reduces the JE element and increases the SE element of the choice process, thereby making the evaluation mode during choice more aligned with that during consumption. To test this prediction, Yang et al. (2011) asked research participants to choose between two digital picture frames, one looking ugly (shining green) and featuring a slightly higher picture resolution, and the other looking nice (metallic silver) and featuring a slightly lower picture resolution. Pretests indicated that look was evaluable in SE and picture resolution was not. Half of the participants were encouraged to directly compare the two frames side by side during choice. The other half were not allowed to do so; instead, they had to examine one frame at a time, with a break inbetween. In support of our prediction, participants in the latter condition were happier during consumption, because more of them chose the nice-looking frame and look mattered more than resolution during SE consumption.

Suboptimal choices like these implicate systematic "mispredictions." As we have mentioned, there appears to be a fundamental problem with predicted utility: people choosing under JE appear to forecast their subsequent accrual of utility as if it too will occur under JE rather than SE and that the same attributes are salient or get attention. This misprediction occurs not only because predictors and 
experiencers are in different evaluation modes but also because predictors fail to put themselves in the evaluation mode of the experiencers. The inability to put oneself in the shoes of others or oneself in another situation was first put forth in a seminal article by Loewenstein (1996; see also Loewenstein, O'Donoghue \& Rabin, 2003).

Another example of prediction errors due to evaluation modes comes from a study by Morewedge et al. (2010). Participants either predicted or experienced a relatively minor event, the eating of potato chips. In both cases, there was another food in the background, either an inferior food -- sardines, or a superior food -chocolate. The authors found that compared with experiencers, predictors were more influenced by the food in the background.

In contrast to the previous studies, the experiencers, like the predictors, were also faced with multiple items, and therefore by design, the experiencers were also in JE. Yet they naturally ignored the item in the background and focused only on the item they were experiencing. Therefore, in effect, they were in SE. The main insight from the Morewedge et al. study is that even if predictors and experiencers are both faced with multiple items, predictors naturally put themselves in the JE mode, comparing across the items, yet experiencers naturally put themselves in the SE mode, focusing primarily on the item they are consuming.

It is critical to note that we do not claim that forcing predictors making predictions under SE would necessarily lead to more accurate forecasts of experienced utility. Our emphasis is rather on the shifting salience and evaluability of attributes between the decision phase and the consumption phase. Now conditions have to be formulated under which specific attributes are relatively overweighted in JE or relatively underweighted in SE (and vice versa).

\section{A3. The Relationship Between Income and Happiness}

One of the most celebrated findings in the happiness literature, attributed to Richard Easterlin, is the observation that when real income increases across generations, happiness does not (e.g., Easterlin, 1974; 1995). ${ }^{3}$ The Easterlin

${ }^{3}$ The empirical claim has recently been challenged; see Stevenson \& Wolfers (2008) and Easterlin et al. (2010). 
finding is often attributed to hedonic adaptation or increasing aspirations (see, e.g., Clark, Frijters \& Shields, 2008; Diener \& Biswas-Diener, 2002; Easterlin, 2010; Frederick \& Loewenstein, 1999; Stutzer, 2004). Though these explanations are surely well-placed, the notion of evaluation modes provides a simple complementary explanation. The lack of correlation between income and happiness across generations may arise because absolute income and living standard are low in evaluability and each generation's hedonic reaction to its income and living standard is largely a matter of SE, i.e., an evaluation of the relative income position at the time. Of course, people in a new generation may occasionally compare themselves with their previous generation, but this comparison would not make the new generation happier, because the previous generation might also have occasionally compared themselves with their previous generation.

More recent research (Hsee et al., 2009) has made a distinction between two types of variables which many people care about and seek to improve: variables that are inherently evaluable, such as ambient temperature, amount of sleep, availability of friends, and those that are not inherently evaluable, such as amount of income (above a certain threshold), horsepower of a car, and square footage of a home. The research proposes and shows that improving inherently-evaluable variables for everyone over time increases the happiness of everyone, but improving inherently-inevaluable variables for everyone over time is merely a zerosum game.

\section{A4. Behavioral Models Describe Prediction, and Classical Theories Describe Consumption}

Since their introduction, prospect theory (Kahneman \& Tversky, 1979) and allied behavioral accounts have usually been treated as alternatives to normative, classical analyses. Essentially, it has been argued that the principles articulated by behavioral models are descriptively accurate, and that the principles articulated by classical analyses are largely descriptively inaccurate. Here, however, on the basis of results like those of Morewedge et al. (2010) and other studies we will shortly 
review, we are putting forward a conjecture. ${ }^{4}$ Behavioral and classical normative accounts may not be alternatives to one another. Instead, the two types of models may simply describe different evaluation modes; one may apply to choice and predicted utility while the other applies to actual accrual of utility during consumption.

A fundamental assumption of classical models is the notion that the carriers of value are final outcomes; that is, people care about and respond to end states. ${ }^{5}$ On the other hand, a key departure for many behavioral models is the notion that the carriers of value are relative changes; that is, people care about gains and losses from a given reference point.

Morewedge et al.'s study suggests that in predictions the carriers of utility are indeed relative gains (chips rather than the inferior sardines) and relative losses (chips rather than the superior chocolate). People do appear to code and react to their future experiences not as "eating chips" per se, but as either "eating chips rather than chocolate" or "eating chips rather than sardines." It is only given such coding of the potential outcomes in terms of relative position that predictions may differ in the first place. Yet, Morewedge et al.'s study also suggests that in consumption the carriers of utility are end states, the taste of the chips. Critically, when people actually eat chips, they do not experience the chips differently given one scenario rather than the other; in actual experience all that seems to matter is the end state. It is chips and only chips that are consumed and that yield utility. In generally, predictions often occur in JE and are sensitive to reference information. In contrast, consumption often occur in SE and are insensitive to reference information.

By our conjecture, then, the principles underlying prospect theory and related behavioral models are indeed more accurate descriptions of choices than

\footnotetext{
${ }^{4}$ See also Loewenstein, O'Donoghue \& Rabin (2003) who argue that loss aversion is a projection bias as people underestimate adaptation to new circumstances.

5 The economic framework can well be extended to deal with procedural utility complementing traditional accounts of outcome utility (Frey, Benz \& Stutzer, 2004). It is taken into account that people have preferences about procedures that lead to outcomes. This also involves the evaluation procedures (e.g., JE or SE) under which people make decisions.
} 
are classical accounts. Ironically, though, they are accurate descriptions of choices that often depend on inaccurate predictions of experienced utility - and that are thus often suboptimal choices. In some sense, behavioral models may be accurate scientific theories of people's inaccurate lay theories of utility accrual.

\section{A5. Misallocation Due to Prediction Bias}

Prediction errors, whether due to evaluation mode or due to other reasons, systematically affect people's allocation of scarce resources. This subsection emphasizes this economic consequence for different applications and mentions some additional aspects leading to utility misprediction.

Many economic decisions are best understood as trade-offs that involve the allocation of money, effort and time. Then, for at least two alternatives, predictions about consumption experience are necessary. Following our framework, these predictions are formed in JE and can systematically differ in their adequacy. If people choose options according to a biased evaluation, their experienced utility will be lower than what they could otherwise enjoy. Moreover, they consume different goods with different attributes and pursue different activities than in a situation where either no option in the choice set poses a prediction problem or the degree of prediction bias is similar across alternatives.

Asymmetric prediction biases are most likely if trade-offs across life domains are to be undertaken. People often overestimate experienced utility from material consumption, because they underestimate the power of hedonic adaption to material living standards (see, e.g., van Praag, 1993 and Stutzer, 2004). In contrast to positive experiences derived from material goods, positive experiences from social, challenging and autonomous activities are less susceptible to hedonic adaptation as they are constantly renewed. Accordingly, in trade-offs, too much weight is given to material goods relative to goods and activities that involve social engagement, or provide for the experience of competence and autonomy (Stutzer \& Frey, 2007).

This is consistent with the general claim that people overvalue income relative to leisure and that the "work-life balance" of individuals today is distorted. People are induced to work too much and to disregard other aspects of life. This 
proposition has been forcefully put forward for the United States, where individuals are said to be "overworked" (Schor, 1991). A related issue is status from conspicuous consumption. Competing for status involves negative externalities and therefore too much effort (from an aggregate perspective) is invested in gaining status and acquiring "positional goods" (Frank, 1985; 1999). If there is a comparatively large prediction bias in experience from consumption, the distortions of competing for status in consumption are magnified.

There is a range of further phenomena, which fit into the framework of asymmetric prediction bias. The prediction bias arising because people underestimate adaptation to new situations has been neatly introduced in theoretical models of intertemporal decision-making (Loewenstein, O'Donoghue \& Rabin, 2003). These models can help to understand misguided purchase of durable goods or consumption profiles with too much consumption early on in life.

Utility misprediction might also help to better understand individual choices that all involve a trade off with commuting (our example in section A2). The commuting decision involves the trade-off between the salary or the quality of housing on the one hand and commuting time on the other hand. Rational utility maximizers only commute when they are compensated. However, when people overestimate utility from goods serving extrinsic desires because they are salient, they are expected to opt for too much commuting and suffer lower experienced utility. In an empirical test using data on reported subjective well-being, people's decision to commute for longer or shorter hours was analyzed (Frey and Stutzer, 2012). It is found that commuting is far from being fully compensated. Moreover, people do not adapt to commuting but seem to adapt to a higher labor income. If this asymmetry is neglected in trade-offs, suboptimal choices result.

There is a long tradition of scholarship arguing that individuals tend to focus too much on material goods and disregard goods providing non-material benefits (see Lane, 1991; Lebergott, 1993). Most importantly, Scitovsky (1976) claimed that "comfort goods" are over-consumed compared to goods providing "stimulation". The former are described as defensive activities, providing protection from negative affect. They consist of the consumer goods achieved through rapid productivity growth. In contrast, stimulation comes from creative activities 
providing novelty, surprise, variety and complexity. These aspects emphasize the renewal of pleasurable experiences. According to Scitovsky, stimulation is at a competitive disadvantage relative to comfort goods because there is a higher cost of access to them and consumers are myopic about the future benefits from stimulating activities. The argument about systematic misallocation in consumption, however, also fits in with a framework of asymmetric prediction bias as immediately accessible acquisition utility puts comfort goods to an advantage relative to stimulation that might even require some consumption capital.

\section{Summary}

Inconconsistencies between predicted and experienced utilities, including those stemming from JE-SE differences, are important causes of suboptimal choices, just like mental accounting and narrow bracketing (on choice bracketing see, e.g., Read, Loewenstein \& Rabin 1999). ${ }^{6}$ While conceptually different, both phenomena deal with mistakes that arise because choices are susceptible to the framing of decisions.

Most people believe that more of a desirable outcome is better. They thus relentlessly pursue more - jobs with more income, cameras with more pixels, cars with more power, and homes with more square-footage. Misprediction and suboptimal choice may both lie at the root of such "more-seeking" and stymie its success. Predictions and choices occur relatively more in JE, and utility is experienced relatively more in SE. Under JE, people expect more to be better. Under SE, people who possess more may not experience more as better (if what they have chosen more of is no longer salient when they consume) and may thus not achieve more happiness. Life teaches us all that the pursuit of more is not the pursuit of happiness. The research we have reviewed elaborates on that lesson.

\section{B. Decision Rules}

The previous section reviewed evidence suggesting that people often fail to choose the optimal option because they fail to accurately predict which option will

${ }^{6}$ Similar to our argument on JE, Read, Loewenstein \& Rabin (1999, p. 192) note that people can too broadly optimize "because bracketing facilitates the consideration of factors that are given little weight during narrow bracketing, it can exacerbate errors people make in anticipating the role these factors play in their experienced well-being." 
yield the highest experienced utility. In this section, we examine another cause of suboptimal choice, the tendency to base choices on salient rules rather than on predicted utility.

\section{B1. Choice without Prediction of Utility}

In a landmark study, Simonson (1990) asked one group of participants to make simultaneous choices of three snacks; they would consume the first snack immediately, the second snack in one week's time, and the third snack in two weeks' time. He asked a second group of participants to make sequential choices of a snack just before each of these three consumption occasions. Most simultaneous choosers decided to have a variety of snacks, whereas most sequential choosers decided to have their (apparent) favorite snack on every one of the three consumption occasions. That is, simultaneous choosers showed a tendency towards variety seeking, whereas sequential choosers showed a tendency against variety seeking.

The different choices formed by simultaneous and sequential choosers suggest that at least one of these groups will be experiencing a level of utility that is lower than what she or he could achieve. In reviewing the contrast between JE and $\mathrm{SE}$, we suggested that in that domain, biases in utility prediction were the source of incongruency between choice and experienced utility. It may be natural, then, to surmise that systematic biases in utility prediction may be implicated in the different choices formed by Simonson's sequential and simultaneous choosers. Clearly, different choices could arise if either simultaneous choosers or sequential choosers do not accurately forecast experienced utility.

Critically, however, Simonson's study also included a third group of participants. The results revealed by this third group appear to rule out the possibility of systematically faulty utility predictions and rule in an even more intriguing hypothesis - the lack of utility predictions. Simonson's third group participated at the same time as the simultaneous choosers. Rather than being asked to make choices, this group was asked to predict what the experienced utility in the three occasions would be like under different scenarios. Incredibly, the predictors forecast better feelings with low variety than with high variety. The 
implication is that simultaneous choosers could predict, if asked, that lesser variety would yield a better experience and that greater variety would yield a worse experience. Yet, they chose greater variety. Why would they do such a thing?

We suggest that simultaneous choosers simply did not base their decisions on predictions of experience. That is, simultaneous choosers formed their choices on a basis other than a prediction of ensuing utility. In particular, we suggest that simultaneous choosers came to a decision by applying a seemingly appropriate rule: seek variety in most circumstances (a related hypothesis was put forward by Ratner, Kahn \& Kahneman, 1999).

Indeed, much research indicates that decision makers often fail to base their decisions on predicted utility. Instead they base their decisions on salient rules or principles (e.g., Ames, Flynn \& Weber, 2004; Drolet 2002; Drolet, Luce, Simonson 2009; March, 1994; Prelec \& Herrnstein, 1991; Ratner, Kahn, and Kahneman 1999; Rottenstreich \& Kivetz 2006; Simonson, 1989; Simonson \& Nowlis, 2000).

For instance, Amir \& Ariely (2007) observed that most people predicted greater happiness from purchasing a ticket for a concert that would occur one week after the day of purchase rather than later the same night, presumably because a week's delay would allow for anticipation and savoring of the experience. Nevertheless, most people were unwilling to pay extra for a concert one week into the future compared to a concert later that night. Why would people not pay for something that they know will enhance their utility? Amir and Ariely argue that such decisions arise from reliance on a "don't pay for delays" rationale as opposed to pure predicted utility. ${ }^{7}$

A suggestive related example was offered much earlier by Arkes \& Blume (1985). These authors asked participants to suppose that they had purchased a $\$ 100$ ticket for a weekend ski trip to one locale and a $\$ 50$ ticket for a weekend ski trip to another locale. Unfortunately, it turned out that the two trips were for the same weekend. The tickets were not refundable, and thus the participants had to choose which of the two tickets to use and which to let go unused. Though participants believed the lower price trip would be more enjoyable, the majority

\footnotetext{
${ }^{7}$ An anonymous referee suggested the alternative norm "pay the same for the same good regardless of the timing".
} 
chose to take the more expensive trip. Arkes and Blume argue that this pattern of preferences reflects appeals to a "waste not" rationale. If so, we would again have an instance in which a decision is made by the application (or over-application) of an appealing rule - even when this rule yields a lower level of experienced utility.

Another related phenomenon is what Hsee et al. (2003) term "lay rationalism," a pattern by which participants choose a seemingly rational option (e.g., one that is financially more valuable) over an alternative which, when asked, they agree would make them happier. One such demonstration draws on decades of research suggesting that people prefer improving sequences over deteriorating sequences (e.g., Ariely \& Carman, 2003; Ariely \& Zauberman, 2003; Loewenstein \& Prelec, 1993; Loewenstein \& Sicherman, 1991). In one study (Hsee et al., 2003), participants were offered a choice between two sets of four dinners that were to be enjoyed over a four-week period. In one set, the dinners increased in price over the course of the four weeks, but the total overall monetary value of the dinners (i.e., the sum of their prices) was relatively lower. In the second set, the four dinners decreased in price over the course of the four weeks, but the total overall monetary value of the four dinners was relatively higher. Participants predicted that they would experience greater enjoyment from the set of dinners with increasing yet lower overall prices but tended to choose the set of dinners with the decreasing yet higher overall prices.

The famous "taxicab" study by Camerer et al. (1997) can also be interpreted as reflecting rule-based choice rather than prediction-based choice. In that study, Camerer et al. observed that novice New York City taxi drivers tended to adopt a particular daily income target and to work only until they hit their target each day. Following such a rule is suboptimal, because it means working many hours when demand for taxicabs is low and few hours when demand is high. Indeed, experienced taxi drivers worked longer hours when demand was high than when it was low, as appropriate. By our analysis, novice cab drivers do not formulate a prediction of demand, perhaps because they are simply not knowledgeable enough to do so or do not have a natural inclination to do so. In the absence of a prediction, they devolve to rule-based behavior. Experienced cab drivers, in 
contrast, can and do form a prediction and base their work decisions on this prediction.

The demonstrations just reviewed are quite diverse but share a critical similarity. In all these demonstrations people are forming choices that, when asked, they explicitly predict will yield suboptimal utility levels. Thus, these decisions appear to proceed without the formation of a utility prediction or at least not on the basis of predicted utility. Instead, the basis for such decisions appears to be some salient rule or rationale. Whenever choices are formed on the basis of rules or other considerations that neglect predicted utility, choices may likely fail to maximize experienced utility.

\section{B2. Rules as an Antidote to Impulsivity}

An impulsive decision is one that selects an option offering a satisfactory experience that is available in the near term over an alternative that offers a better overall experience but is only available with some significant delay. Consider a choice between chocolate cake and fruit salad for dessert. The chocolate cake may offer greater immediate gratification, but the fruit salad may contribute to the avoidance of obesity and other health problems and to a longer life. Thus, though opting for the chocolate cake may offer a more satisfactory immediate experience, opting for the fruit salad may with time offer a better overall experience.

Impulsive decisions are almost certainly multiply determined. People may behave impulsively because they do not understand the consequences of their behavior. For example, some people smoke, because they do not believe that smoking leaves them vulnerable to many pernicious diseases. In many instances, however, people make impulsive choices with a keen awareness of the potential consequences - they simply cannot resist the temptation (e.g., Kivetz \& Simonson, 2002b; Loewenstein, 1996; O'Donoghue \& Rabin, 1999; Thaler \& Shefrin, 1981).

The topic of impulsivity has received extensive attention in both psychology and economics (see Ainslie, 2001; Baumeister \& Heatherton, 1996; Baumeister \& Vohs, 2003 \& 2004; Christensen-Szalanski, 1984; Prelec \& Herrnsten, 1991; Rachlin \& Raineri, 1992; Schelling, 1980; 1984; Thaler, 1980; Thaler \& Sherfrin, 1981). We would like to offer a somewhat novel two-step analysis of this topic that 
stresses the role of rules, and which surprisingly suggests the conjecture that excessively patient behavior may be as prevalent as excessively impulsive behavior.

First, we suggest that many rules are instituted in part as antidotes against impulsivity. That is, rules play a role as self-control mechanisms that aid the decision-maker to maximize delayed happiness or overall experienced utility. "Waste not," "don't pay for delays," and "lay rationalism" are all rules that clearly promote less impulsive decisions over more impulsive decisions. Adherence to these and similar principles can tether the decision maker to a policy or guideline that deters rash reactions.

For instance, suppose an employee who is approaching retirement and who has little savings receives a cash bonus. Suppose further that she can either save the bonus for retirement or spend it on a luxury cruise. Taking the cruise is enjoyable in the short run, but saving the money may be a greater benefit in the long run. Opting for the cruise would constitute an impulsive decision. Instead, lay rationalism would encourage the soon-be-retiree to save the money. Although a few decision rules encourage immediate gratification (e.g., "life is short, enjoy it while you can"), most rules have at least some of the flavor of self-control mechanisms.

The observation that rules may be instantiated as self-control mechanisms accords with the notion that reliance on rules may often simplify the task of making many related decisions. By providing an overarching policy or guideline, rules can eliminate the need to carefully ponder (or the possibility of rashly reacting to) each of very many similar decisions. Though the policy or guideline instantiated by some rule may not yield the maximum level of experienced utility, it may, at low cost, generate a portfolio of decisions that does yield a generally sufficient (and perhaps even high) level of experienced utility. Indeed, by instantiating a measure of selfcontrol and discipline, adherence to a rule or principle only enables a level of longterm experienced utility that is higher than would otherwise be feasible. 


\section{B3. When Are We Excessively Impulsive and When are We Excessively Patient?}

Though this view of rules casts them in a good light, there is an important caveat which forms the second step of our analysis. Rules are a simplifying tool; by enacting an overarching policy one may indeed avoid thinking about or reacting to each minute decision that one encounters. But how does one know which situations call for the application of a particular rule and which do not? How can one ensure, for example, that one is foreclosing rashness in a circumstance where one really should do so? The use of rules may simplify some matters, but understanding which rules are relevant when is no simple matter (for an excellent account of this issue, see Kahneman, 2011).

When one considers this perspective, it seems that many rules and selfcontrol devices can help in some circumstances and hurt in others. If the options the decision maker faces entail a genuine tradeoff between immediate and delayed utility, self-control rules will by definition be helpful. Otherwise, the application of such rules may be harmful. To illustrate, consider again the soon-to-be retiree. If she is poor, taking a cruise and saving for retirement indeed entail a tradeoff between immediate and delayed utility. In this circumstance, self-control rules may well enable her to experience greater delayed utility and possibly also greater overall experienced utility. On the other hand, if the soon-be-retiree is wealthy, taking a cruise may dominate saving for retirement. In this circumstance, taking a cruise will not affect her financial condition, and she is thus not facing the same kind of tradeoff between immediate and later utility. If she nevertheless adheres to rules that entail self-control in such a circumstance, she may lower her overall experienced utility. She may never be able to enjoy the fruits of her riches.

More generally, we speculate that individuals frequently do not effectively distinguish between circumstances that involve a tradeoff of immediate and delayed utility versus circumstances that do not. People's behavior may thus be too uniform to effectively maximize their experienced individual well-being. Most critically, the notion that rules are difficult to apply properly and frequently engender excessively uniform behavior provides a framework for predicting both when people will be excessively impulsive and when they will be excessively patient. In particular, if 
people's behavior is excessively uniform then (i) they will be too impulsive when short-term goals entail substantial long-term costs, and (ii) they will be excessively patient when a short-term gain does not entail substantial long-term costs. Thus, though the economics literature has largely focused on impulsivity, our analysis suggests that excessive patience may also be a significant impediment to people's pursuit of happiness. ${ }^{8}$

Corroboration of this conjecture is provided by recent research. Kivetz \& Simonson (2002a,b; Kivetz \& Keinan 2006) were perhaps the first to emphasize problems of hyperopia or excessive patience. They documented several instances in which many consumers tended to deprive themselves of indulgence or leisure in favor of utilitarian goods or work - to an apparently excessive degree. Indeed, the consumers in question often employed pre-commitments and rules to force indulgence. For example, these consumers sometimes chose compensation in the form of hedonic luxury items over cash compensation of equal or greater value and explained their decision as intended to guarantee that the reward not be spent on necessities.

Shu $(2004,2005)$ reviews a vast array of evidence suggesting that retirement savings are buffered too long. For instance, the elderly often underspend their savings and die with more money than they intended (Carroll \& Samwick, 1997; Palumbo 1999). In addition, it appears that the elderly vastly underutilize reverse mortgages, which allows people to "cash out" the equity in their homes without having to repay the loan until after death. Studies estimate that the demand for reverse mortgages should be anywhere from 3 to 9 million households, while actual use of reverse mortgages has ranged from 6,000 to 12,000 per year (Venti \& Wise, 1991) whereby the inheritance motive is arguably difficult to separate.

Returning to domains that are closer to consumption than savings, Shu (2008; see also Shu and Gneezy, 2010) argues that for most consumption items, the default behavior is to consume quickly, but that there are some items for which

${ }^{8}$ A notable exception is the work by Bénabou \& Tirole (2004) on willpower and personal rules. In their model, an individual can be too patient because he interprets each choice as a test of his willpower and is concerned of appearing too impulsive to himself what would reduce his self-control. 
the default is to not consume now. These items are the ones for which two rules seem applicable. The first rule is "occasion matching," and is based on the desire to maximize experienced utility by choosing the specific consumption occasion that best matches the item - i.e., an expensive bottle of wine should be consumed on a very special night when it will most be enjoyed. The second rule emphasizes an "option preservation" rationale. It stems from the desire to minimize the chance of immediate loss; the old tomato should be eaten tonight (and the better one saved) if it will otherwise go to waste. Note that both of these rules have as a purpose the maximization of experienced utility - yet they may still engender excessively patient behavior that fails to actually maximize it.

An important feature of items for which the default is not to consume now is their framing within a larger temporal context. The timing decision is seen as existing within a sequence of many such decisions; if the option is not used now, there are multiple later opportunities waiting (thus the desires to occasion match and preserve options). For example, using frequent flier miles now means that they will not be available for a future special trip, and using the new tomato now (and discarding the old one) means that there will be no tomatoes available tomorrow.

Shu's rules can lead to a type of "hoarding" behavior, where items are saved just because they might be needed someday. The hoarder fears being unprepared for a future need or losing an important item that might be useful someday. Indeed, a substantial industry in clutter removal advice has evolved to deal with this frequent behavior. As one expert on clutter writes,

"...Those three words, 'just in case,' have caused more people to accumulate excess clutter than any other words I know of. Just in case I need an empty jar/spare rubber band/Spanish dictionary/cat carrier; or just in case I learn to play the piano/lose some weight/move to another climate/learn to sew/become an artist/find a partner, implies that we don't trust that we have what we need now.... [O]ne of the most important things we can learn is to live in the present moment. If we are so wrapped up in the future, we use 
up the energy that we could devote to what our needs are right now."

Work on the phenomenon of cupboard castaways is also consistent with this hoarding behavior (Wansink, Brasel \& Amjad, 2000). Cupboard castaways are often obscure kitchen items that are saved as "just in case" ingredients for rare recipes. The individual may purchase the item for a specific need, but when the need fails to materialize, the item is preserved rather than discarded. Some estimates indicate that up to $12 \%$ of grocery purchases may end up as castaways.

Finally, note that Amir and Ariely's demonstration of consumers' reluctance to pay for delays, Arkes and Blume's demonstration of consumers' reliance on "waste not, want not" rules, Camerer et al.'s cab driver study, and Hsee et al.'s demonstrations of lay rationalism all constitute specific instances in which people, to their own detriment, are excessively rigid in following a rule that is meant to obviate impulsivity.

\section{Summary}

In this section we have examined suboptimal choices that occur not because of utility misprediction but because of the absence of utility prediction. Simonson's participants predict that they would enjoy consistency over variety - yet they choose variety. Camerer et al.'s novice taxicab drivers are apparently not apt to form a prediction of demand - so they supply their labor in a way that is insensitive to market conditions. Hsee's participants would prefer to receive one set of dinners, but adherence to lay rationalism steers them to a less preferred option. These examples demonstrate how reliance on rules can often be too rigid. To the extent that understanding which rules should be applied to which circumstances is a difficult matter, people will frequently overapply rules in a way that harms their consumption experience. Perhaps most importantly, rules that are meant to temper self-control problems of excessive impulsivity may frequently be invoked in circumstances where they are not warranted and actually yield excessive patience. 


\section{Concluding Remarks}

We have reviewed two distinct types of suboptimal choices. The first arises when choices follow predicted utility, but predicted utility is inconsistent with experienced utility. In particular, choices and predicted utility may reflect JE considerations, but actual experience may proceed under SE. The second arises when people fail to make predictions about utility and instead base their choices on salient decision rules. These decision rules are often applied to situations which they do not fit very well.

Our review has been guided by the belief that economists may be able to leverage their analytic tools and methods to generate prescriptions that solve many instances of suboptimal choice. That is, in our opinion analysis including experienced individual well-being may suggest numerous prescriptive possibilities. For instance, a sophisticated understanding of just how utility is predicted and experienced under JE and SE may bring forth many possibilities for improving people's choices.

Future economic research of suboptimal choice may also shed light on two issues of which we do not currently have much knowledge. First, why do people often fail to recognize suboptimal choices? At least part of the answer lies in the very nature of counterfactuals. There are some suboptimal choices that people may simply never have the opportunity to learn about. For instance, if a person always makes a certain choice under JE, they might never experience the SE-optimality of some non-chosen alternatives. On the other hand, there are likely many suboptimal choices that people do detect on their own. Their subsequent regret about mistakes may drive them towards undoing their suboptimal choice. It would certainly be useful to delineate the conditions under which suboptimal choices will persist and the conditions under which they may sometimes be eliminated.

Second, we currently know very little about the market consequences of suboptimal choices. We would like to only raise two thoughts. Suppose that a consumer has bought a product in JE choice and is not happy with it during SE consumption. Will she be less likely to buy the same product in the future? We do not know. It is possible that even though she is unhappy, she will not realize that she could be happier if she had chosen an alternative product and therefore she 
may not regret her decision and will continue to buy the same product in the future. That is essentially the point we made in the previous paragraph, that is, people do not know the counterfactuals and therefore do not learn. On the other hand, it is also possible that she is so unhappy with the bought product during consumption that she will not buy the same product again, regardless of whether she is aware of the counterfactuals.

Consider another scenario, if a seller of consumer electronics faces a onetime transaction with a consumer, she might try to sell the consumer some expensive extra gadget with technical advantages that are easy to evaluate but are unlikely to provide much extra experienced utility. To do so, she would want to make sure to present the entire transaction in as maximally a JE manner as possible. On the other hand, if the seller expects a long-term relationship with the consumer, she might present the items in SE so that the consumer is more likely to make an optimal choice rather than a suboptimal choice, avoid any regret about his or her decisions, and thus continue his or her relationship with the seller. In general, the mode of interactions between sellers and buyers and thus the endogenous prevalence of suboptimal choices may be determined by market factors and subject to market dynamics.

The debate about whether people do or do not make suboptimal choices, where standard economic assumptions are pitted against intuition and other social sciences, is not a mere academic exercise. This debate may have critical policy implications. If people never make mistakes, then no intervention or paternalism is needed. If people indeed make systematic mistakes, then extreme notions of consumer sovereignty should perhaps be re-examined and in some cases abandoned in favor of more paternalistic approaches (Frey \& Stutzer, 2006; Thaler \& Sunstein 2008).

In our review, we have given priority to experienced utility as a criterion of individual welfare. However, we are not identifying consumption utility with happiness. We are aware that different indicators of individual welfare capture different aspects of people's pursuit of happiness. For example, people might gain utility from exerting will power because they have resisted a temptation. Or, they may judge their live favorably because their life course contributes to positive self- 
signaling, identity, goal completion, mastery or meaning (for economic analyses of such motives see, e.g., Akerlof \& Kranton 2000 and Loewenstein 1999). We believe, however, that experienced utility is in many cases a highly relevant evaluation standard for consumption choices.

Regardless of whether experienced utility is the ultimate criterion, this article has reviewed evidence that decision and experienced utilities can be systematically different and that people do not always make decisions that maximize experienced utility. We hope that future analysis in this vein can further refine our understanding of the optimality of people's choices and thereby contribute to people's pursuit of happiness. 


\section{References}

Ainslie, G. (2001). Breakdown of Will. New York: Cambridge University Press.

Akerlof, G. \& Kranton, R. (2000). Economics and Identity. Quarterly Journal of Economics, 115(3), 715-733.

Akerlof, G. \& Shiller R.J. (2009) Animal Spirits: How Human Psychology drives the Economy, and why it matters for Global Capitalism. Princeton: Princeton University Press.

Ames, D., Flynn, F.J. \& Weber, E.U. (2004). It's the Thought that Counts: On Perceiving How Helpers Decide to Lend a Hand. Personality and Social Psychology Bulletin, 30(4), 461-74.

Amir, O. \& Ariely, D. (2007). Decision by rules: The Case of Unwillingness to Pay for Beneficial Delays. Journal of Marketing Research, 44, 142-152.

Ariely, D. \& Carman, Z. (2003). Summary Assessment of Experiences: The Whole Is Different from the Sum of Its Parts. In Loewenstein, G. et al. (eds.), Time and Decision: Economic and Psychological Perspectives on Intertemporal Choice (pp. 323-349). New York: Russell Sage Foundation.

Ariely, D., Loewenstein, G. \& Prelec, D. (2003). Coherent Arbitrariness. Stable Demand Curves without Stable Preferences. Quarterly Journal of Economics, 118, 73-106.

Ariely, D. \& Zauberman, G. (2003). Differential Partitioning of Extended Experiences. Organizational Behavior and Human Decision Processes, 91, 128-139.

Arkes, H.R. \& Blume, C. (1985). The Psychology of Sunk Cost. Organizational Behavior and Human Decision Processes, 35, 124-140.

Baumeister, R.F. \& Heatherton, T. F. (1996). Self-Regulation Failure: An Overview. Psychological Inquiry, $1,1-15$.

Baumeister, R.F. \& Vohs, K.D. (2003). Willpower, Choice, and Self-Control. In Loewenstein, G., Read, D. et al. (eds.), Time and Decision: Economic and Psychological Perspectives on Intertemporal Choice (pp. 201-216). New York: Russell Sage Foundation.

Baumeister, R.F. \& Vohs, K.D (eds). (2004). Handbook of Self-Regulation: Research, Theory and Applications. New York: Guilford Press.

Bazerman, M.H., Loewenstein, G.F. \& White, S.B. (1992). Reversals of Preference in Allocation Decisions: Judging an Alternative Versus Choosing Among Alternatives. Administrative Science Quarterly, 37, 220-240.

Benjamin, D.J., Heffetz, O., Kimball, M.S. \& Rees-Jones, A. (forthcoming, 2012). What Do You Think Would Make You Happier? What Do You Think You Would Choose? American Economic Review.

Bénabou, R. \& Tirole, J. (2004). Willpower and Personal Rules. Journal of Political Economy, 112(4), 848-856.

Camerer, C.F., Babcock, L., Loewenstein, L. \& Thaler, R. (1997). Labor supply of New York city cab drivers: One day at a time. Quarterly Journal of Economics, 111, 408-41.

Camerer, C., Loewenstein, G. \& Rabin, M. (eds.) (2004). Advances in Behavioral Economics. New York: Russell Sage Foundation.

Carroll, C.D. \& Samwick, A.A. (1997). The Nature of Precautionary Wealth. Journal of Monetary Economics, 40, 41-71. 
Christensen-Szalanski, J.J.J. (1984). Discount Functions and the Measurement of Patient's Values: Women's Decisions during Childbirth. Medical Decision Making, 4, 47-58.

Clark, A.E., Frijters, P. \& Shields, M. (2008). Relative Income, Happiness and Utility: An Explanation for the Easterlin Paradox and other Puzzles. Journal of Economic Literature, 46(1), 95-144.

De Cremer, D., Zeelenberg, M. \& Murnighan, J.K. (2006). Social Psychology and Economics. Mahwah, N.J.: Lawrence Erlbaum.

Di Tella, R. \& MacCulloch, R. (2006). Some Uses of Happiness Data in Economics. Journal of Economic Perspectives, 20(1), 25-46.

Diener, E. \& Biswas-Diener, R. (2002). Will Money Increase Subjective Well-Being? Social Indicators Research, 57, 119-169.

Diener, E., Helliwell, J.F. \& Kahnemann, D. (2010). International Differences in Well-Being. Oxford: Oxford University Press.

Drolet, A. (2002). Inherent Rule Variability in Consumer Choice: Changing Rules for Change's Sake. Journal of Consumer Research, 29(3), 293-305.

Drolet, A., Luce, M.F. \& Simonson, I. (2009). When Does Choice Reveal Preference? Moderators of Heuristic vs. Goal Based Choice. Journal of Consumer Research, 36(1), 137-147.

Easterlin, R.A. (1974). Does Economic Growth Improve the Human Lot? Some Empirical Evidence. In David, P. \& Reder, M.W. (eds.), Nations and Households in Economic Growth: Essays in Honour of Moses Abramovitz (pp. 89-125). Palo Alto, CA: Stanford University Press.

Easterlin, R.A. (1995). Will Raising the Incomes of all Increase the Happiness of all? Journal of Economic Behavior and Organization, 27, 35-48.

Easterlin, R.A. (2010). Happiness, Growth and the Life Cycle. New York: Oxford University Press.

Easterlin, R.A., McVey, L.A., Switek, M., Sawangfa, O. \& Zweig, J.S. (2010). The Happiness-Income Paradox Revisited. Proceedings of the National Academy of Sciences of the USA, 107, 22463-22468.

Fehr, E. \& Goette, L. (2007). Do Workers Work more if Wages are High? Evidence from a Randomized Field Experiment. American Economic Review, 97, 298317.

Frank, R.H. (1985). Choosing the Right Pond: Human Behavior and the Quest for Status. New York: Oxford University Press.

Frank, R.H. (1999). Luxury Fever: Why Money Fails to Satisfy in an Era of Excess. New York, NY: Free Press.

Frederick, S. \& Loewenstein, G.F. (1999). Hedonic Adaptation. In Kahneman, D., Diener, E. \& Schwarz, N. (eds.), Well-being: The Foundations of Hedonic Psychology (pp. 302-329). New York: Russell Sage Foundation.

Fredrickson, B.L. \& Kahneman, D. (1993). Duration Neglect in Retrospective Evaluations of Affective Episodes. Journal of Personality and Social Psychology, 65, 45-55.

Frey, B.S. \& Stutzer, A. (2002). What Can Economists Learn from Happiness Research? Journal of Economic Literature, 40(2), 402-435.

Frey, B.S., Benz, M. \& Stutzer, A. (2004). Introducing Procedural Utility: Not Only What, but Also How Matters. Journal of Institutional and Theoretical Economics, 160(3), 377-401. 
Frey, B.S. \& Stutzer, A. (2006). Mispredicting Utility and the Political Process. In McCaffery, E.J. \& Slemrod, J. (eds.), Behavioral Public Finance (pp. 113140). New York: Russell Sage Foundation.

Frey, B.S. \& Stutzer, A. (eds.) (2007). Economics and Psychology. A Promising New Cross-Disciplinary Field. Cambridge, MA: MIT Press.

Frey, B.S. \& Stutzer, A. (2012). Economic Consequences of Mispredicting Utility. Mimeo, University of Basel.

Gilbert, D.T. (2006). Stumbling on Happiness. New York: Knopf.

Gilbert, D.T., Driver-Linn, E. \& Wilson, T.D. (2002). The Trouble with Vronsky: Impact Bias in the Forecasting of Future Affective States. In Barrett, L.F. \& Salovey, P. (eds.), The Wisdom in Feeling: Psychological Processes in Emotional Intelligence (pp. 114-143). New York: Guilford.

Gilbert, D.T. \& Wilson, T.D. (2009). Why the Brain Talks to Itself: Sources of Error in Emotional Prediction. Philosophical Transaction of the Royal Society $B_{\text {, }}$ $364,1335-1341$.

Helliwell, J. (2006). Well-Being, Social Capital and Public Policy: What's New? Economic Journal, 116(510), C34-C45.

Hsee, C.K. (1996). The Evaluability Hypothesis: An Explanation for PreferenceReversal between Joint and Separate Evaluations of Alternatives. Organizational Behavior and Human Decision Processes, 67, 247-257.

Hsee, C.K. \& Hastie, R. (2006). Decision and Experience: Why Don't We Choose What Makes Us Happy? Trends in Cognitive Sciences, 10(1), 31-37.

Hsee, C.K. \& Zhang, J. (2004). Distinction Bias: Misprediction and Mischoice due to Joint Evaluation. Journal of Personality and Social Psychology, 86, 680-695.

Hsee, C. K. \& Zhang, J. (2010). General Evaluability Theory. Perspectives on Psychological Science.

Hsee, C.K., Loewenstein, G.F., Blount, S. \& Bazerman M. H. (1999). PreferenceReversals between Joint and Separate Evaluations of Options: A Review and Theoretical Analysis. Psychological Bulletin, 125, 576-591.

Hsee, C.K., Rottenstreich, Y. \& Xiao, Z. (2005). When is More Better? On the Relationship between Magnitude and Subjective Value. Current Directions in Psychological Science, 14(5), 234-237.

Hsee, C. K., Yang, Y., Li, N. \& Shen, L. (2009). Wealth, Warmth and Well-Being: Whether Happiness Is Relative or Absolute Depends on Whether It Is About Money, Acquisition, or Consumption. Journal of Marketing Research, 46(3), 396-409.

Hsee, C.K., Zhang, J., Yu, F. \& Xi, Y. (2003). Lay Rationalism and Inconsistency between Predicted Experience and Decision. Journal of Behavioral Decision Making, 16(4), 257-272.

Kahneman, D. (2000). Experienced Utility and Objective Happiness: A MomentBased Approach. In Kahneman, D. \& Tversky, A. (eds.), Choices, Values, and Frames (pp. 673-692). Cambridge, England: Cambridge University Press.

Kahneman, D. (2011). Thinking, Fast and Slow. New York: Farrar, Strauss and Giroux.

Kahneman, D., \& Riis, J. (2005). Living, and Thinking about it: Two Perspectives on Life. In Huppert, F., Keverne, B. \& Baylis, N. (eds.), The Science of Well Being. Oxford: Oxford University Press.

Kahneman, D., \& Snell, J. (1992). Predicting a Changing Taste: Do People Know 
What They Will Like? Journal of Behavioral Decision Making, 5, 187-200.

Kahneman, D. \& Thaler, R.H. (2006). Anomalies: Utility Maximization and Experienced Utility. Journal of Economic Perspectives, 20(1): 221-234.

Kahneman, D. \& Tversky, A. (1979). Prospect Theory: An Analysis of Decision Under Risk. Econometrica, 47, 263-292.

Kahneman, D., Diener, E. \& Schwarz, N. (eds.) (1999). Well-Being: Foundations of Hedonic Psychology. New York: Russell Sage Foundation Press.

Kahneman, D., Krueger, A. B., Schkade, D. A., Schwarz, N., \& Stone, A. A. (2004). A Survey Method for Characterizing Daily Life Experience: The Day Reconstruction Method (DRM). Science, 306, 1776-1780.

Kahneman, D., Ritov, I. \& Schkade, D. (1999). Economic Preferences or Attitude Expressions? An Analysis of Dollar Responses to Public Goods. Journal of Risk and Uncertainty, 19, 203-235.

Kahneman, D., Wakker, P. \& Sarin, R. (1997). Back to Bentham? Explorations of Experienced Utility. Quarterly Journal of Economics, 112, 375-405.

Kivetz, R. \& Keinan, A. (2006). Repenting Hyperopia: An Analysis of Self-Control Regrets. Journal of Consumer Research, 33, 73-82.

Kivetz, R. \& Simonson, I. (2002a). Earning the Right to Indulge: Effort as a Determinant of Customer Preferences toward Frequency Program Rewards. Journal of Marketing Research, 39, 155-170.

Kivetz, R. \& Simonson, I. (2002b). Self-Control for the Righteous: Towards a Theory of Pre-Commitment to Indulgence. Journal of Consumer Research, 29, 199-217.

Lane, R.E. (1991). The Market Experience. Cambridge: Cambridge University Press.

Layard, R. (2005). Happiness: Lessons From a New Science. New York: Penguin Press.

Lebergott, S. (1993). Pursuing Happiness: American Consumers in the Twentieth Century. Princeton: Princeton University Press.

List, J.A. (2002). Preference Reversals of a Different Kind: The More is Less Phenomenon. American Economic Review, 92, 1636-1643.

Loewenstein, G. (1996). Out of Control: Visceral Influences on Behavior. Organizational Behavior and Human Decision Processes, 65, 272-292.

Loewenstein, G. (1999). A Visceral Account of Addiction. In Elster, J. \& Skog, O. (eds.), Getting Hooked: Rationality and Addiction. Cambridge, U.K.: Cambridge University Press.

Loewenstein, G. \& Sicherman, N. (1991). Do Workers Prefer Increasing Wage Profiles? Journal of Labor Economics, 9, 67-84.

Loewenstein, G. \& Prelec, D. (1993). Preferences for Sequences of Outcomes. Psychological Review, 100, 91-108.

Loewenstein, G. \& Schkade, D. (1999). Wouldn't it be Nice? Predicting Future Feelings. In Kahneman, D. Diener, E. and Schwarz, N. (eds.), Well-Being: The Foundations of Hedonic Psychology. New York: Russell Sage Foundation.

Loewenstein, G., O'Donoghue, T. \& Rabin, M. (2003). Projection Bias in Predicting Future Utility. Quarterly Journal of Economics, 118, 1209-1248.

March, J. (1978). Bounded Rationality, Ambiguity, and the Engineering of Choice. Bell Journal of Economics, 9(2), 587-608.

March, J. (1994). A Primer on Decision Making: How Decisions Happen. New York: Free Press. 
Mellers, B. (2000). Choice and the Relative Pleasure of Consequences. Psychological Bulletin, 126, 910-924.

Mellers, B. \& McGraw, P. (2004). Anticipated Emotions as Guides to Choice. Current Directions in Psychological Science, 10, 210-214.

Morewedge, C.K., Gilbert, D.T., Myrseth, K.O.R., Kassam, K.S. \& Wilson, T.D. (2010). Consuming Experiences: Why Affective Forecasters Overestimate Comparative Value. Journal of Experimental Social Psychology, 46(6), 986992.

O'Donoghue, T. \& Rabin, M. (1999). Doing it Now or Later. American Economic Review, 89, 103-124.

Palumbo, Michael (1999). Uncertain Medical Expenses and Precautionary Savings Near the End of the Life Cycle, Review of Economic Studies, 66, 395-421.

Prelec, D. \& Herrnstein, R. (1991). Preferences or Principles: Alternative Guidelines for Choice. In Zeckhauser, R.J. (ed.), Strategy and Choice. Cambridge, MA: MIT Press.

Rabin, M. (1998). Psychology and Economics. Journal of Economic Literature, 36(1), 11-46.

Rachlin, H. \& Raineri, A. (1992). Irrationality, Impulsiveness and Selfishness as Discount Reversal Effects. In Loewenstein, G. \& Elster, J. (eds.), Choice Over Time (pp. 93-118). New York: Russell Sage Foundation.

Ratner, R.K., Kahn, B.E. \& Kahneman, D. (1999). Choosing Less-Preferred Experiences for the Sake of Variety. Journal of Consumer Research, 26, 1-15.

Read, D., Lowenstein, G. \& Rabin, M. (1999). Choice Bracketing. Journal of Risk and Uncertainty, 19(1-3), 171-197.

Rottenstreich, Y. \& Kivetz, R. (2006). Decision Making without Likelihood Judgment. Organizational Behavior and Human Decision Processes, 101, 74-88.

Schelling, T.C. (1980). The Intimate Contest for Self-Command. The Public Interest, 60, 94-118.

Schelling, T.C. (1984). Self Command in Practice, in Theory and in a Theory of Rational Choice. American Economic Review, 74, 1-11.

Schkade, D.A. \& Kahneman, D. (1998). Does Living in California Make People Happy? A Focusing Illusion in Judgments of Life Satisfaction. Psychological Science, 9, 340-346.

Schor, J.B. (1991). The Overworked American: The Unexpected Decline of Leisure. New York, NY: Basic Books.

Scitovsky, T. (1976). The Joyless Economy: An Inquiry into Human Satisfaction and Consumer Dissatisfaction. Oxford: Oxford University Press.

Seligman, M.E.P. \& Csikszentmihalyi, M. (2000). Positive Psychology: An Introduction. American Psychologist, 55, 5-14.

Sen, Amartya (1982). Choice, Welfare, and Measurement. Cambridge, Mass: Harvard University Press.

Sheldon, K.M., Kashdan, T.B. \& Steger, M.F. (2011). Designing Positive Psychology: Taking Stock and Moving Forward. Oxford: Oxford University Press.

Shu, S. (2004). Two Essays Regarding the Influence of Temporal Spacing on Judgment and Usage Timing. Ph.D. Dissertation, University of Chicago.

Shu, S. (2005). Choosing to Consume Later: Determinants of Future-Biased Choice. In Menon, G. \& Rao, A.R. (eds.), Advances in Consumer Research, 32 (pp. 67-68). Duluth, MN:Association for Consumer Research. 
Shu, S. (2008). Future-biased Search: The Quest for the Idea. Journal of Behavioral Decision Making, 21, 352-377.

Shu, S. and Gneezy, A. (2010). Procrastination of Enjoyable Experiences. Journal of Marketing Research, 47, 933-944.

Simonson, I. (1989). Choice Based on Reasons: The Case of Attraction and Compromise Effects. Journal of Consumer Research, 16, 158-174.

Simonson, I. (1990). The Effect of Purchase Quantity and Timing on VarietySeeking Behavior. Journal of Marketing Research, 27, 150-162.

Simonson, I. \& Nowlis, S. M. (2000). The Role of Explanations and Need for Uniqueness in Consumer Decision Making: Unconventional Choices Based on Reasons. Journal of Consumer Research, 27, 49-68.

Stevenson, B. \& Wolfers, J. (2008). Economic Growth and Subjective Well-Being: Reassessing the Easterlin Paradox. Brookings Papers on Economic Activity, $1-87$.

Stutzer, A. (2004). The Role of Income Aspirations in Individual Happiness. Journal of Economic Behavior and Organization, 54(1), 89-109.

Stutzer, A. \& Frey, B.S. (2007). What Happiness Research Can Tell Us About SelfControl Problems and Utility Misprediction. In Frey, B.S. \& Stutzer, A. (eds.), Economics and Psychology. A Promising New Cross-Disciplinary Field (pp. 169-195). Cambridge: MIT Press.

Stutzer, A. \& Frey, B.S. (2010). Recent Advances in the Economics of Individual Subjective Well-Being. Social Research: An International Quarterly, 77(2), 679-714.

Thaler, R.H. (1980). Toward a Positive Theory of Consumer Choice. Journal of Economic Behavior and Organization, 1, 39-60.

Thaler, R.H. \& Shefrin, H.M. (1981). An Economic Theory of Self-Control. Journal of Political Economy, 89, 392-406.

Thaler, R.H. \& Sunstein, C.R. (2008). Nudge. Improving Decisions About Health, Wealth, and Happiness. Yale: Yale University Press.

van Boven, L., Dunning, D. \& Loewenstein, G. (2000). Egocentric Empathy Gaps between Owners and Buyers: Misperceptions of the Endowment Effect. Journal of Personality and Social Psychology, 79, 66-76.

van Boven, L. \& Loewenstein, G. (2003). Projection of Transient Drive States. Personality and Social Psychology Bulletin, 29, 1159-1168.

van Praag, B.M.S. (1993). The Relativity of the Welfare Concept. In Martha Nussbaum, M. \& Sen, A. (eds.), The Quality of Life (pp. 362-385). New York: Oxford University Press.

van Praag, B.M.S. \& Ferrer-i-Carbonell, A. (2004). Happiness Quantified: A Satisfaction Calculus Approach. Oxford: Oxford University Press.

Veenhoven, R. (1993). Happiness in Nations: Subjective Appreciation of Life in 56 Nations 1946-1992. Rotterdam: Erasmus University Press.

Venti, S.F. and Wise, D.A. (1991). Aging and the Income Value of Housing Wealth. Journal of Public Economics, 22, 371-97.

Wansink, B., Brasel, S A. \& Amjad, S. (2000), The Mystery of the Cabinet Castaway: Why We Buy Products We Never Use, Journal of Family and Consumer Science, 92(1), 104-108

Wilson, T. D. \& Gilbert, D. (2003). Affective Forecasting. Advances in Experimental Social Psychology, 35, 345-411. 
Yang, A. X., Hsee, C. K., Liu, Y. \& Zhang, L. (2011). The Supremacy of Singular Subjectivity: Improving Decision Quality by Removing Objective Specifications and Direct Comparisons. Journal of Consumer Psychology, 21, 393-404. 